\title{
Rural household income diversification in developing countries: A Case study of Eritrea
}

\author{
Menghistab Debesai ${ }^{1,2, *}$ \\ ${ }^{1}$ Don State Technical University, 1, Gagarina, sq., 344003, Rostov-on-Don, Russia \\ ${ }^{2}$ Hamelmalo Agricultural College, Eritrea P.O. Box 397
}

\begin{abstract}
Following a baseline survey in Eritrea, income diversity study among rural farming households was conducted. Two steps analysis was followed during the analysis of income levels and diversity status: (1) the regional level, and (2) the household level. Simpson Index of Diversification was used to calculate the diversity status both at household and regional level. The analysis indicated that income diversification was pervasive in all regions and households irrespective of income levels. Although income diversification was more in high income groups, it was also substantial with the "extreme" and "low income" groups. The difference was that low income groups diversified in less risky ventures as a necessity, whereas the high income groups diversify even in more risky ventures as a choice. A Tobit regression model indicated that level of education, ethnicity, household size, gross income, income per capita, and access to credit had a positive relationship with income diversity. Others such as the age of the household head, dependency ratio and size of land ownership had a negative relationship. Therefore, policy measures need to be directed towards creating a conducive condition taking into consideration the multiple sources of income, socioeconomic, demographic and institutional conditions of rural farming households.
\end{abstract}

\section{Introduction}

The concept of diversification conveys different meaning to different people at different levels $[1,2]$. Broadly speaking, livelihood diversification refers to the expansion of the range of rural activities outside the farm and is seen as a dynamic adaptation process created through pressures and opportunities [3]. Specifically, income diversification refers to an increase in the number of sources of income or the balance among the different sources. It means, on the one hand, that total income of a household accrues to more than one sources and on the other hand, no one source is much dominant compared to the other sources [4]. Income diversification also referred to as a risk management and coping strategy meant to mitigate the effects of economic hardship. The simplest interpretation of farm diversification as an objective is thus, farmers seek to generate a portfolio of income from activities with different degrees of risk, expected returns, liquidity and seasonality, and adjust their output mix accordingly [5].

\footnotetext{
${ }^{*}$ Corresponding Author: robeljan20134@gmail.com
} 
Plenty of evidence is available that diversification on average contributes around half of all rural incomes in low-income countries [2, 6]. Those farm households with relatively higher income often diversify by choice whereas the majority and poor ones diversify as a necessity [6]. Diversification possesses positive attributes for poverty and vulnerability reduction. It increases human capital in terms of experience, skills and willingness to innovate. It generates earnings by widening the options open to the household and increases the liquid asset in the form of cash resources that can be flexibly used. It contributes to lessening vulnerability by improving risk and reducing the adverse consumption effects of seasonality. In general, income diversification improves the livelihoods of many rural people [7]. Most development economists, advocating mainstream economic thinking, assumed that farm output growth would create plentiful nonfarm income-earning opportunities in the rural economy via linkage effects. However, this assumption is no longer justifiable; for many poor rural families, farming on their own are unable to provide a sufficient means of survival [8].

Policy guidelines in Eritrea tend to overlook the existence of diversification by giving more emphasis to policy settings that are straight forward based on definite assumptions as if the livelihood of rural people is determined by only one or two factors and hence this ignores the diverse nature of economic activities. Nevertheless, critical scrutiny of the details of the livelihoods and income generation of households in many rural areas of developing countries indicate that sources of livelihoods and income generation are quite diverse. Unlike the common understanding of many scholars and policymakers, within agricultural societies itself, the livelihood and source of income are far from uniformity [10]. Policy formulations concerning such issues are usually flawed against the reality; the objectives of which are often seen either from a simplicity point of view or maybe sometimes from unawareness. It is, therefore, important to think of the full range of rural income-generating activities, both agricultural and non-agricultural, carried out by rural households. This can improve the understanding of the relationship between various economic activities that take place in the rural areas and their implications to poverty reduction and economic growth.

Accordingly, the objective of the present research was to identify the main sources of income, income status (IS) and diversity status (DS) of the farmers both at regional and household levels and the main factors that determine income diversification.

\section{Methodology}

\subsection{Description of the Study Area}

Eritrea is located in the Horn of Africa, bordered by the Red Sea in the east, Djibouti in the southeast, Ethiopia in the south and Sudan in the west (Figure 1). It has an area of 124,320 $\mathrm{km}^{2}$ (including around 350 islands) and a coastline of 1,200 km (Government of Eritrea, 2005) (Government of Eritrea (2005) 'National Medium Term Investment Programme (NMTIP) January', in National Medium Term Investment Programme (NMTIP).). Administratively, Eritrea is sub-divided into six parts primarily based on geographical location. They are Maekel, Anseba, Gash-Barka, Debub, Northern Red Sea (NRS) and southern Red Sea (SRS) [11]. The livelihoods of the vast majority (70\%) of the Eritrean people depend on agriculture that plays a vital role in the process of economic development and employment $[13,14]$. 


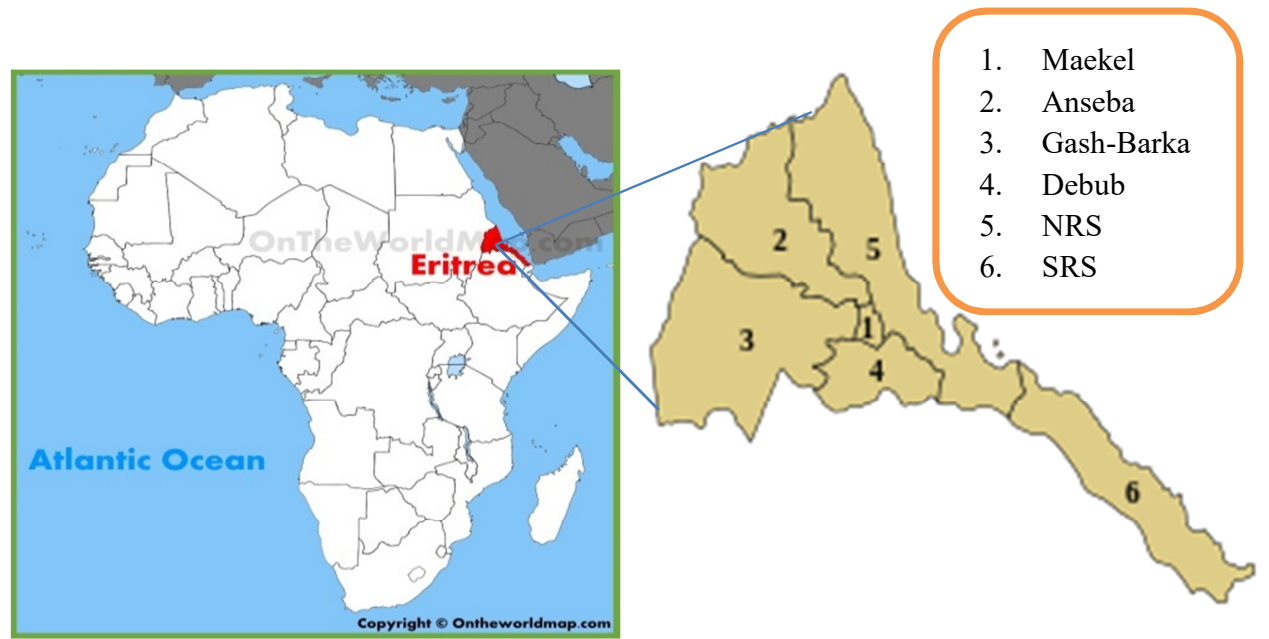

Fig. 1. Map of Eritrea in Africa (Source: Google map).

\subsection{Sampling and data collection}

The paper makes use of household-level cross-sectional data from the 'Baseline Survey of Agricultural Households' conducted in 2016 by the Ministry of Agriculture, Eritrea. This dataset provides information on income from various sources, agricultural and nonagricultural, of farming households, which can be used to analyse the relative income levels, the degree of income diversification and factors that mainly affect income diversification. The sample household's data provide quantitative and qualitative information emphasising on household socioeconomic characteristics, asset endowments, and income-generation.

The survey employed a systematic random sampling method to collect data. The sample size was determined proportionally to the number of households in each region. According to [14], the following formula was applied to collect the total desired sample size for the whole survey.

$$
n=\left(\frac{Z_{\alpha / 2}^{2} p q}{e^{2}}\right)
$$

where $n$ is the total desired sample size for the survey, $Z$ is normal table value, $p$ is estimated proportion of an attribute that is present in the population, $q=(1-p), e$ is the desired level of precision. This equation was used to account for households that vary between sites and the number of households per site. Accordingly, a total of 656 households were selected, out of which, 96 were from NRS, 47 from SRS, 96 from Anseba, 78 from Gash-Barka, 89 from Maekel and 250 from Debub regions.

\subsection{Model specification and method of analysis}

\subsubsection{Measures of income diversification}

According to [15], the commonly used measures of diversification include (i) Index of maximum proportion, (ii) Herfindal Index, (iii) SID, (iv) Ogive Index, (v) Entropy Index, (vi) Modified Entropy Index, and (vii) Composite Entropy Index. Each method has its own 
weaknesses and strengths. Considering the objectives of assessing the extent of diversity within the agricultural activity as well as non-agricultural activity, the SID was preferred for this analysis. The SID is simple and provides a clear distribution of sources and share of activity in a geographical region [16]. Furthermore, SID is an appropriate measurement because (i) it takes into consideration both the number of income sources and the contribution of each source to total household income, and (ii) it is appropriate for a censored data as diversification of income are distributed between 0 and 1 the former being low diversified and the latter being high diversified [16].

The formula for SID goes as follows:

$$
S I D=1-\sum_{i=1}^{n} p_{i}^{2}
$$

where $i=1,2, \ldots n ; n$ is the number of income sources and $p_{i}$ is the proportion of income from $i^{\text {th }}$ source in the total household income. SID is bound by 0 and 1 where 0 indicates complete specialization and 1 signifies complete diversification, and a movement from 0 to 1 indicates an increase in income diversification [17].

Two levels of analysis for diversification are adopted. The first one is an aggregate diversity level used to understand the relative diversity of regions differentiated by geographical location. This is used simply to have an overview of the combined effect of income status and relative diversity of regions in different locations. The following formula is used to calculate IS of regions:

$$
I S=X_{i}-\mu
$$

where $I S$ represents the income status of the $i^{\text {th }}$ region; $X$ represents the mean income of the $i^{\text {th }}$ region; and $\mu$ represents the overall mean income for all regions.

The second level of analysis is the income diversity focused at each household in the study area regardless of their location. In this case, the $I S$ and $D S$ for each household are calculated. The income diversity at the household level is important to carry out regression analysis to identify factors affecting income diversity in farming households.

\subsubsection{Determinants of Income Diversification of Farm Households}

To assess the determinants of income diversification of farm households in rural Eritrea, several factors were considered. The diversification status of each household considered in the sample survey was first calculated using SID formula. SID has a censored distribution in that some data above or below a threshold are misreported at the threshold, and hence lies between 0 to 1[19]. Thus, the Tobit regression model becomes an appropriate estimation method for factors determining the level of diversification. To estimate a model where some observations on the regressand are censored (because they are not observed), Tobit model uses a maximum likelihood (ML) method [20]. In the model, there is some latent process $\left(\mathrm{Y}_{\mathrm{i}}{ }^{*}\right)$ with unbounded support, but we observe only the latent variable [22]. The general formulation is usually given in terms of an index function as follows: 


$$
\begin{aligned}
& Y_{i}^{*}=\beta X_{i}+\varepsilon \\
& Y_{i}=0 \text { if } Y_{i}^{*} \leq 0 \\
& Y_{i}=Y_{i}^{*} \text { if } Y_{i}^{*}>0
\end{aligned}
$$

where $i=1,2, \ldots n, n$ denotes the sample size; $Y_{i}$ represents the dependent variable $S I D$; $Y_{i}^{*}$ is the latent variable only observed for income shares above a threshold $\left(Y_{i}^{*}>0\right) ; X_{i}$ represents a vector of independent variables (such as socioeconomic, demographic and attitudinal variables of the households); $\beta$ is a vector of coefficients to be estimated and $\varepsilon$ is the normally distributed error term. The latent variable model assumes that the error term is independent, identically distributed with zero mean and constant Variance [ $Y_{i}^{*}=\beta X_{i}+\varepsilon$, where $\varepsilon \sim i i d \mathrm{~N}(0,1)]$ with the observed variable $Y_{i}$ generated by the expression given in equation $4[21,22,23]$.

\section{Results and discussions}

\subsection{Descriptive statistics at regional level}

Respondents in the survey revealed that their sources of income are derived from agricultural (crop farming and animal husbandry) and non-agricultural (off-Farm income, forest product, small scale business, wage labour and remittance). The sources differ for each region and household in magnitude and type. Rural population in developing countries derive important income shares from rural nonfarm activities. On average Sub-Saharan African countries derive $30-50 \%$ of their income outside of farming activities [3, 4]. A report by [24] gives a mean figure of $42 \%$ for Sub-Saharan Africa. In this report, the income from non-agricultural sources is a little bit smaller than that given in the literature. The share of different sources of income in percentage is given in Table 1. Overall, income from grain and vegetable sales dominates, comprising (50.5\%) followed by livestock $(30 \%)$, off-farm income $(8.1 \%)$, wage labour $(3.8 \%)$, remittance and small scale business (3.5\%), respectively. Although income sources from agriculture (crop and livestock) generally dominate in all regions, comprising on average about $80 \%$, other non-agricultural sources of income cannot be undermined (Table 1).

Table 1. Share of sources of income by region (\%).

\begin{tabular}{|l|c|c|c|c|c|c|c|}
\hline Sources of income & NRS & SRS & Anseba & Gash-Barka & Maekel & Debub & Mean \\
\hline Grain, vegetables and fruits & 53.8 & 39.8 & 35.9 & 39.9 & 68.4 & 53.8 & 50.5 \\
\hline Livestock & 21.2 & 48.9 & 57.9 & 15.5 & 13.6 & 25.5 & 30.0 \\
\hline Off-farm income & 15.3 & 5.8 & 0.6 & 10.6 & 1.6 & 11.0 & 8.1 \\
\hline Forest product & 1.2 & 0.3 & 0.0 & 3.8 & 0.0 & 0.7 & 0.8 \\
\hline Small scale business & 1.6 & 1.8 & 1.8 & 22.7 & 5.9 & 0.9 & 3.5 \\
\hline Wage labour & 4.6 & 0.4 & 2.3 & 5.8 & 8.5 & 2.9 & 3.8 \\
\hline Remittance & 2.2 & 3.0 & 1.5 & 1.7 & 2.0 & 5.2 & 3.5 \\
\hline
\end{tabular}




\subsection{Regional dimensions of income Status}

Following equation 3, the $I S$ of all regions has been calculated. The overall annual mean $\mathrm{HH}$ income for all regions has been found to be Eritrean Nakfa (ERN) 30507. Regions whose average income less than the overall mean income are regarded as relatively low income regions; whereas regions whose average income greater than the overall mean are relatively high income regions. Accordingly, regions of NRS, SRS, and Gash-Barka, are roughly regarded as relatively low income regions, and Anseba, Debub and Maekel are considered as relatively high income regions (Table 2). This analysis though crude will help to see whether relatively low income regions (LI) diversify more than their counterpart relatively high income regions $(H I)$.

Table 2. Average Income Status (IS) of regions per annum (ERN).

\begin{tabular}{|c|c|c|c|c|c|c|c|c|}
\hline Description & NRS & SRS & Anseba & Gash-Barka & Maekel & Debub & Total & $\begin{array}{c}\text { Overall } \\
\text { mean }\end{array}$ \\
\hline $\mathrm{X}_{\mathrm{i}}$ & 22754 & 11825 & 33798 & 20275 & 35516 & 37737 & 161904 & 30507 \\
\hline $\mathrm{X}_{\mathrm{i}}-\mu$ & -7753 & -18682 & 3291 & -10232 & 5009 & 7230 & & \\
\hline $\mathrm{IS}$ & $\mathrm{LI}$ & $\mathrm{LI}$ & $\mathrm{HI}$ & $\mathrm{LI}$ & $\mathrm{HI}$ & $\mathrm{HI}$ & & \\
\hline $\mathrm{n}$ & 96 & 47 & 96 & 89 & 78 & 250 & 656 & \\
\hline
\end{tabular}

\subsubsection{Income diversification at the regional level}

The dynamics and pattern of rural income diversification may vary considerably across regions. The nature of income diversification depends on the conditions, such as location and level of development and growth of agriculture [25]. It is argued that diversity of income varies with the level of economic development; at a low level of development the households adopt multiple-economic activities and they move towards specialisation as the economy proceeds on the path of development [26]. Another argument on diversification is that diversification takes place at all levels. The difference is that whether diversification takes place as necessity or choice. This is sometimes referred to as being a contrast between survival and choice or between survival and accumulation [3]. Low income groups or the poor may diversify as a matter of survival and the high income groups to accumulate further wealth [3].

Following equation number 2 , the regions were classified dichotomously into a relatively low diversified region (LD) and relatively high diversified region (HD). The DS is calculated at the centre of the overall mean diversity formula. Since SID is bound by 0 and 1 , where 0 indicates complete specialization and 1 signifies complete diversification, the central value 0.5 is used as a reference point for distinguishing between relatively lowdiversified and high-diversified regions. A region whose SID score is above 0.5 achieves a positive value and is regarded as a high-diversified region and vice-versa. $[1,26]$. Thus the DS of a given household or region is calculated as follows:

$$
D S=1-\sum_{i=1}^{n}\left(p_{i}\right)^{2}-0.5
$$

where $1-\sum_{i=1}^{n}\left(p_{i}\right)^{2}$ represents $S I D$ for the $i^{t h}$ region; $i=1,2, \ldots, n$. Accordingly, all regions were categorized as relatively highly diversified in their income. This indicates that the contribution of other sources of income other than the agricultural source is significant. 
In other words, income sources of all regions are pretty highly diversified outside of crop and livestock production (Table 3).

Table 3. Diversity status of the regions.

\begin{tabular}{|c|c|c|c|c|c|c|c|}
\hline Zone & NRS & SRS & Anseba & Gash-Barka & Maekel & Debub & Mean \\
\hline $1-\Sigma\left(\mathrm{P}_{\mathrm{i}}\right)^{2}$ & 0.639 & 0.598 & 0.535 & 0.749 & 0.502 & 0.630 & 0.645 \\
\hline Reference & 0.500 & 0.500 & 0.500 & 0.500 & 0.500 & 0.500 & 0.500 \\
\hline Difference & 0.139 & 0.098 & 0.035 & 0.249 & 0.002 & 0.130 & 0.145 \\
\hline Diversity Status & HD & HD & HD & HD & HD & HD & HD \\
\hline
\end{tabular}

Following the results of DS and IS, all regions were categorized into four classes as follows: (i) relatively high income-high diversification, (HI-HD) (ii) relatively high income-low diversification, (HI-LD) (iii) relatively low income-high diversification, (LIHD) and (iv) relatively low income-low diversification (LI-LD). Accordingly, N/R/Sea, $\mathrm{S} / \mathrm{R} / \mathrm{Sea}$, and Gash-Barka regions fall on the LI-HD group, whereas Debub, Maekel and Anseba regions on the HI-HD group (figure 2).

The combination of income and diversity status is schematically shown separated by quadrants in figure 2. The reference for IS of the regions is the overall mean income, while the reference for DS is 0.5, a mid-value of SID. A region that falls within Quadrant I is categorized as LI-HD, in Quadrant II as HI-HD, and in Quadrant III and IV, LI-LD and HIHD, respectively. The analysis shows that none of the regions falls within quadrant III and IV, which are both locations for low diversity. All the six regions are located within quadrant I and II, indicating that they are in the highly diversified group irrespective of there IS value.

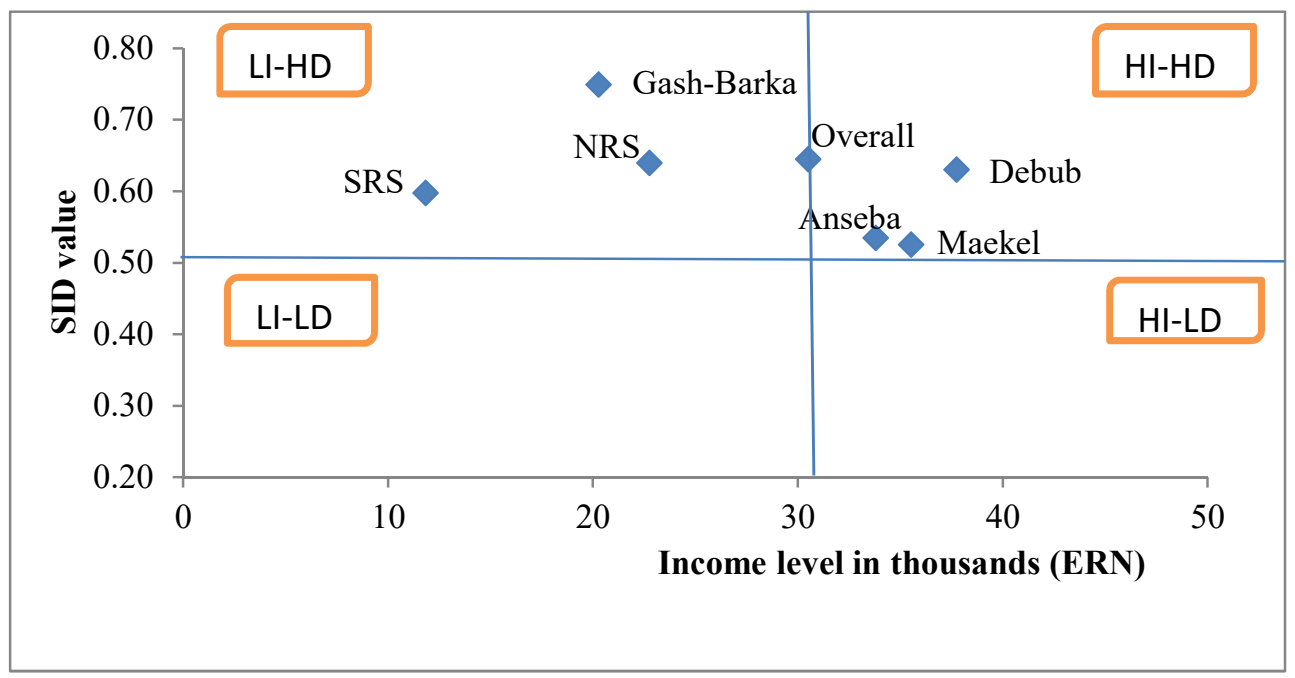

Fig. 2. Schematic presentation of regional dimensions and income diversification Status.

Both farming households in relatively HI regions and relatively LI regions diversify but for different reasons. The reasons that individuals or households diversify their income as a livelihood strategy may be as a matter of survival for the poor and a choice for the well to do [3]. Sometimes this is referred to as "push versus pull" reason in the migration literature $[5,28]$. 
Several factors were considered that affect income DS measured with the SID values. These include socioeconomic, demographic and institutional factors, such as household (HH) Gross Income, HH Per capita income, farm size, dependency ratio, family size, age of $\mathrm{HH}$ head, level of education, gender, marital status, access to market, ethnicity, access to credit, and profession (Table 4). The expected sign of the explanatory variables is given based on literature. In most cases, mixed results are reported.

Table 4. Factors considered to affect income diversification.

\begin{tabular}{|c|c|c|c|}
\hline Variables & Description & Measurement & Expected sign \\
\hline SID & Dependent variable & $\begin{array}{c}0 \text { to } 1 \\
\text { (censored) }\end{array}$ & \\
\hline Age & Age of HH head & $\begin{array}{c}\text { Category } \\
(1-6)\end{array}$ & $(+,-)$ \\
\hline Edu & Education of HH head & $\begin{array}{c}\text { Category } \\
(1-8)\end{array}$ & $(+)$ \\
\hline Marital & Marital Status of HH head & $\begin{array}{c}\text { Category } \\
\text { (married, single, Divorced) }\end{array}$ & $(+,-)$ \\
\hline Gender & Gender of HH Head & $\begin{array}{c}\text { Category } \\
(0 \text { female, } 1 \text { male })\end{array}$ & $(+,-)$ \\
\hline Ethnic & Ethnicity & $\begin{array}{c}\text { Category } \\
(1-9)\end{array}$ & $(+,-)$ \\
\hline HHsize & Family Size & $\begin{array}{c}\text { Number } \\
\text { mean }(6.53)\end{array}$ & $(+,-)$ \\
\hline Dpratio & Dependency Ratio & $\begin{array}{c}\text { Ratio } \\
\text { mean }(0.38)\end{array}$ & $(-)$ \\
\hline HHGI & HH Gross Income & ERN & $(+)$ \\
\hline Inpercap & HH Per capita Income & ERN & $(+)$ \\
\hline Profess & Main stay of HH head & $\begin{array}{c}\text { Category } \\
(1-3)\end{array}$ & $(+,-)$ \\
\hline Farm size & Farm Size of HH & $\begin{array}{c}\text { Hectares (ha) } \\
\text { mean (3.8) }\end{array}$ & $(-)$ \\
\hline Market & Access to Market & $\begin{array}{c}\text { Category } \\
(1=\text { yes, } 0=\text { no })\end{array}$ & $(+)$ \\
\hline Credit & Access to Credit & $\begin{array}{c}\text { Category } \\
(1=\text { yes, } 0=\text { no })\end{array}$ & $(+,-)$ \\
\hline
\end{tabular}

\subsubsection{Category of SID at household level}

Figure 3 shows the distribution of SID regardless of income group of the households. Overall the households are classified into "non-diversified", (SID $=0$ ), "slightly diversified" (SID $=0.0019-0.3000)$, "moderately diversified" (SID $=0.3010-0.5000)$ and "highly diversified" (SID $>0.500$ ). Only $31.25 \%$ of the households fall within the nondiversified category. The rest $68.75 \%$ were found to be slightly to highly diversified whose SID greater or equal to 0.0019 (Figure 3). The mean value of SID for "non-diversified", "slightly diversified", "moderately diversified" and "highly diversified", are 0, 0.183, 0.437 , and 0.601 , respectively. 


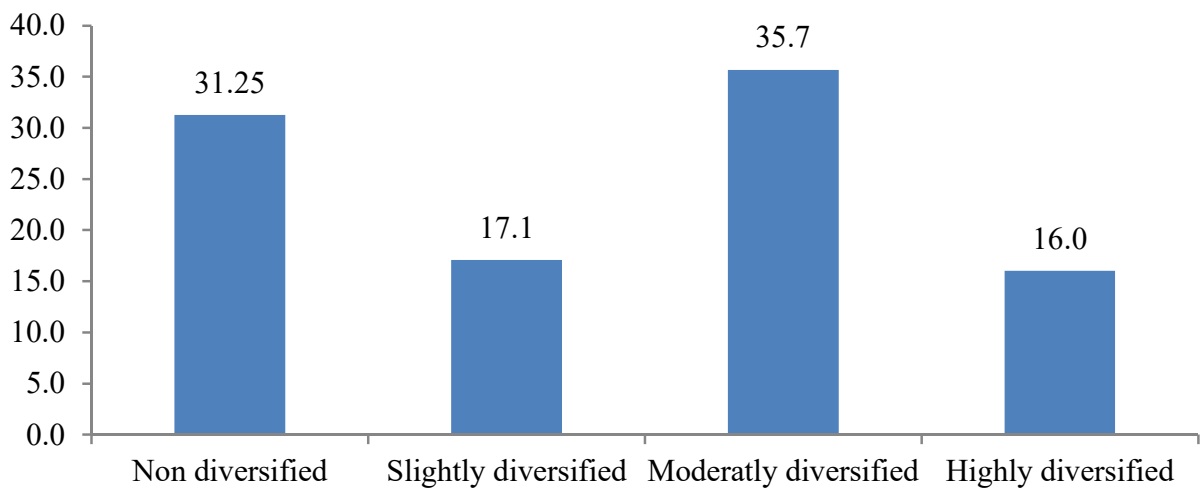

Fig. 3. Distribution of HH by DS (\%).

A scatter diagram in (Figure 4) shows the concentration of the SID values around zero on the $\mathrm{X}$-axis indicating the existence of censored values of the dependent variable from below. The non-diversified income groups are concentrated around that point, consisting of around $31.25 \%$ of the sample population. Immediately above zero up to 0.300 , sparsely distributed SID values are observed comprising of about $17 \%$ indicating a slightly diversified income. Between 0.300 and 0.500 it is observed again a concentration of SID values comprising $35.7 \%$, representing a moderately diversified group. Above 0.500 values are scattered the highly diversified income groups comprising of $16 \%$ (Figure 3 and 4 ).

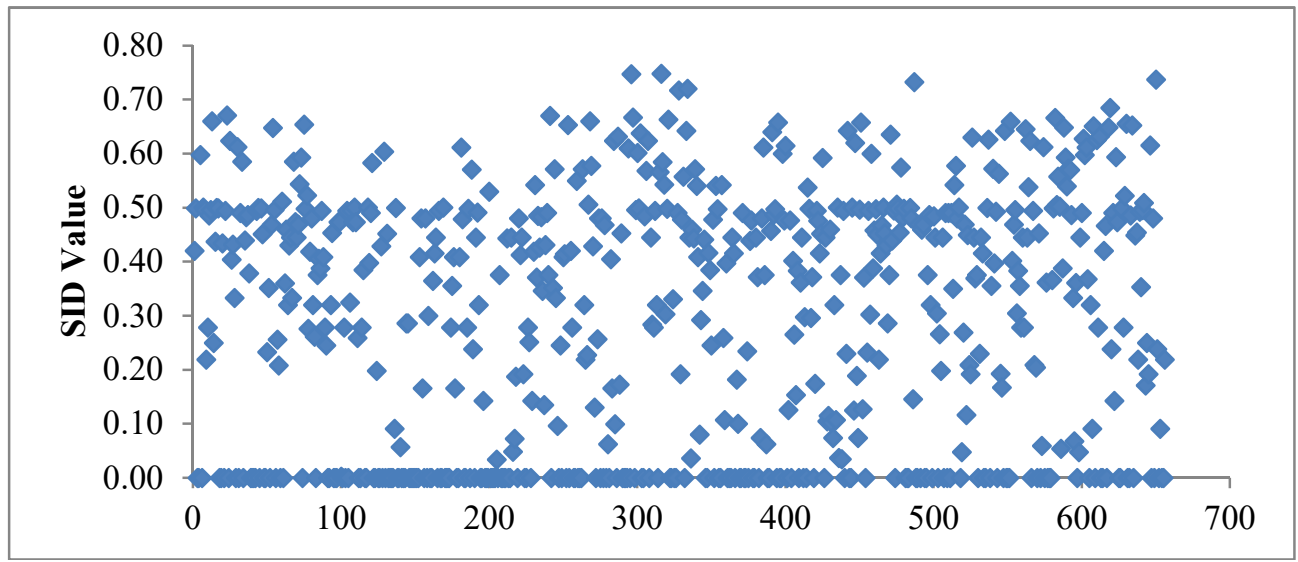

Fig. 4. Distribution of SID values over the sample size.

\subsubsection{Distribution of SID values by income groups}

The average family size for the rural farming households has been calculated to be 6.53 , with a median of 6 . This is important to calculate the average income per capita for each income group. Income groups have been identified as "extremely low income", "low income", "moderate income" and "high income" depending on where the household's income falls within the quartiles of income as arranged in descending order. The first quartile with extremely low income group is regarded as destitute whose annual average $\mathrm{HH}$ gross income is ERN 4000 and average HH per capita income of ERN 613 which is equivalent to USD 267 and 40.8, respectively. The daily income per capita is ERN 1.678 equivalent to USD 0.11. Income groups whose annual average $\mathrm{HH}$ gross income is ERN 
13000 and average HH per capita income of ERN 1991, which is equivalent to USD 866.7 and 132.7 respectively, are classified as low income groups or poor. Their daily per capita income is ERN 5.45 equivalent to USD 0.364. The third quartile income groups are classified as moderate income groups whose annual average gross $\mathrm{HH}$ income and $\mathrm{HH}$ per capita income are ERN 26600 and 3981.6, respectively. Their daily per capita income is ERN 10.91 equivalent to USD 0.727. The fourth quartile groups are regarded as high income groups or rich whose average $\mathrm{HH}$ gross income and income per capita are ERN 94600, and 14486.98, respectively. Their daily per-capita income counts to ERN 39.73 equivalent to USD 2.65. A report by [27] indicates that the gross domestic product GDP per capita of Eritrea ranged between USD 907.30 in 1998 and USD 522.40 in 1992, which is equivalent to per capita income per day between USD 1.43 and 2.48. In the present report, only the "high income" group earns per capita income within this range. The rest $75 \%$ of the households earn their income less than a dollar per day (Table 5).

Table 5. Per capita income by quartiles.

\begin{tabular}{|l|c|c|c|c|}
\hline \multicolumn{1}{|c|}{ Quartiles } & $\begin{array}{c}\text { Annual gross } \\
\text { income } \\
\text { (ERN) }\end{array}$ & $\begin{array}{c}\text { Annual per } \\
\text { capita income } \\
\text { (ERN) }\end{array}$ & $\begin{array}{c}\text { Daily per } \\
\text { capita } \\
\text { income } \\
\text { (ERN) }\end{array}$ & $\begin{array}{c}\text { Daily per capita income } \\
\text { (USD) (Official } \\
\text { exchange rate is 1 USD } \\
\text { = 15 ERN) }\end{array}$ \\
\hline $\begin{array}{l}1^{\text {st }} \text { (extreme } \\
\text { low income) }\end{array}$ & 4000.00 & 613.00 & 1.678 & 0.112 \\
\hline $\begin{array}{l}2^{\text {nd }}(\text { low } \\
\text { income) }\end{array}$ & 13000.00 & 1991.00 & 5.454 & 0.364 \\
\hline $\begin{array}{l}3^{\text {rd }} \text { (moderate } \\
\text { income) }\end{array}$ & 26000.00 & 3982.00 & 10.91 & 0.727 \\
\hline $\begin{array}{l}4^{\text {th }} \text { (high } \\
\text { Income) }\end{array}$ & 94600.00 & 14501.00 & 39.73 & 2.65 \\
\hline
\end{tabular}

\subsubsection{Distribution of DS by income group}

The concern here is to understand whether low income groups of HH diversify more than their counterpart high income groups and vice-versa. As depicted on (Figure 5), about $34.7 \%$ of the extremely low income groups, $73.8 \%$ of the low income group, $78.1 \%$ of the moderate income group, and $88.5 \%$ of the high income group have, respectively, from slightly to highly diversified income. This suggests that even the destitute and the poor have the incentive to diversify. The difference is that the well to do diversify for choice while the poor do it for necessity [3]. As [24] put it, the poor are more likely to diversify in favour of less risky income sources and activities, whereas the well to do households are in a more favourable position to diversify even with risky ventures since they can use their wealth for self-financing and as a buffer against negative income shocks. 


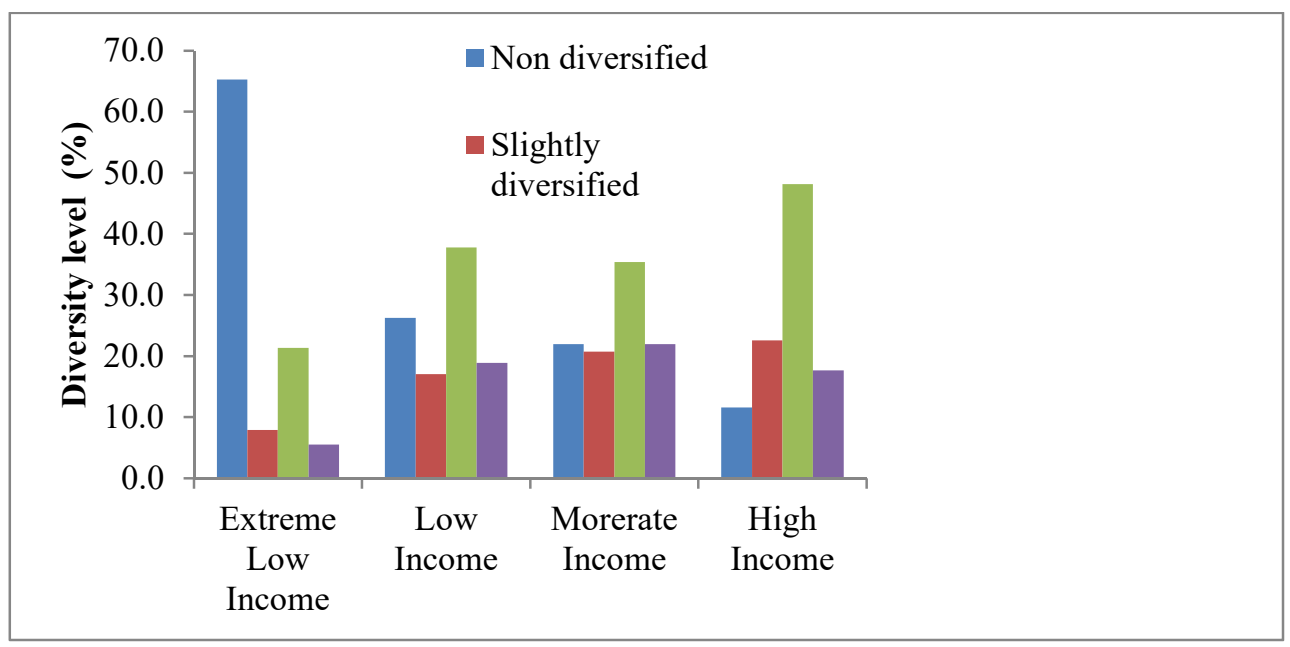

Fig. 5. Distribution of DS by income group.

\subsection{Econometric results}

The values obtained from the calculation of SID that explain the income diversity status of households was regressed against many socioeconomic explanatory variables to understand if these variables had any impact on income diversification. Tobit model with STATA 14 software was used to regress the dependent variable as the value of SID was censored between 0 and 1. From the regression, a high level of Chi-Square with (Prob $>\chi^{2}=0.0$ ) was found indicating that the model as a whole was significant at $95 \%$ level of significance (Table 6).

There is a mixed result in the literature concerning factors that affect income diversification. A study in India indicates that while agriculture remains a dominant income source for the majority of the agricultural households, non-farm income like wages and salaries comprise a significant proportion of income for relatively richer households. The report further found that households in low income, low-diversification region indicated that those who are at subsistence level do not diversify much [25]. A report from Ghana indicates that age of household heads, number of years of education, female headed households, number of extension visits, household income per capita, productive asset owned, and the nature of road were significant in influencing income diversity [29]. Similarly, a report from Ethiopia found that age, education and distance to the proximate market to have a significant negative effect on farm household's decision to participate in non-agricultural livelihood diversification activities [30].

The Food and Agricultural Organization [31] shows that an increasing share of households have participated in non-agricultural activities as one moves across the wealth quintiles from poorer to wealthier. Within non-farm activities, the strongest positive relationship was observed for wage labour; and better-off households were more likely to participate in non-agricultural wage labour [32]. The mixed findings from these studies justify that further empirical investigation is required on the forces driving income diversification in rural farming households.

In this particular study, some of the demographic characteristics such as marital status and gender were found to have no significant effect on income diversification. Similarly, the variable profession as explained by agro-pastoralist, pastoralist or crop farmer, doesn't show significant difference indicating that the households are engaged more or less in a similar manner as pastoralists, agro-pastoralists and crop farmers. Access to the market also 
does not show a significant effect on the diversity status, suggesting underdevelopment of market structure. Other factors such as the age of the household head, level of education, ethnicity, household size, dependency ratio, farm size, gross income and income per capita have a significant impact on income diversification (Table 6).

Following Table 6, regression results are presented as follows:

Table 6. Estimates of coefficients from Tobit regression results.

\begin{tabular}{|c|c|c|c|c|c|c|}
\hline $\begin{array}{r}\text { LR C } \\
\text { Pseud }\end{array}$ & $2(13)$ & $\begin{aligned} & \text { Numb } \\
&= 251.54 \\
&= 0.3861 \\
&\end{aligned}$ & f obser & $\begin{array}{r}=65 \\
1 \\
L\end{array}$ & $\begin{array}{l}\text { Chi2 } \\
\text { dihood }\end{array}$ & $\begin{array}{c}0.000 \\
-199.999 \\
\end{array}$ \\
\hline Variables & Coef. & Std. Err. & $\mathbf{t}$ & $\mathbf{P}>|\mathbf{t}|$ & {$[95 \% \mathrm{C}$} & Interval] \\
\hline age & $-0.02544 * *$ & 0.01207 & -2.11 & 0.035 & -0.04913 & -0.00174 \\
\hline edu & $0.00197 *$ & 0.00107 & 1.84 & 0.066 & -0.00013 & 0.0040661 \\
\hline marital & 0.021915 & 0.021992 & 1 & 0.319 & -0.02127 & 0.0651 \\
\hline gender & 0.015306 & 0.034881 & 0.44 & 0.661 & -0.05319 & 0.083801 \\
\hline ethnic & $0.01233 * *$ & 0.004646 & 2.65 & 0.008 & 0.003208 & 0.021453 \\
\hline HHsize & $0.05424 * *$ & 0.004427 & 12.25 & 0.000 & 0.045547 & 0.062933 \\
\hline dpratio & $-0.21951 * *$ & 0.033982 & -6.46 & 0.000 & -0.28624 & -0.15278 \\
\hline HHGI & $2.12 \mathrm{E}-06^{* *}$ & $4.69 \mathrm{E}-07$ & 4.53 & 0.000 & $-3.04 \mathrm{E}-06$ & $-1.20 \mathrm{E}-06$ \\
\hline inpercap & $1.33 \mathrm{E}-05^{* *}$ & $2.67 \mathrm{E}-06$ & 4.98 & 0.000 & $8.04 \mathrm{E}-06$ & $1.85 \mathrm{E}-05$ \\
\hline profess & 0.000411 & 0.001236 & 0.33 & 0.74 & -0.00202 & 0.002838 \\
\hline farmsize & $-.28912 * *$ & .0135064 & -21.41 & 0.000 & -.315649 & -.262604 \\
\hline market & -0.00252 & 0.027742 & -0.09 & 0.928 & -0.057 & 0.051951 \\
\hline credit & $0.093649 * *$ & 0.02294 & 4.08 & 0.000 & 0.048603 & 0.138695 \\
\hline constant & -0.09526 & 0.096192 & -0.99 & 0.322 & -0.28415 & 0.09363 \\
\hline sigma & 0.269513 & 0.009654 & & & 0.250555 & 0.288471 \\
\hline
\end{tabular}

Where: ** Significant at $95 \%$ Confidence Interval $(\alpha=0.05)$. *Significant at $90 \%$. Confidence Interval $(\alpha=0.10)$.

Level of education: The coefficient of educational level was found to be positive and statistically significant at the 0.10 probability level. The educational level of the household head is likely to increase the income diversification, because education tends to open more employment opportunities for income generation such as non-farm wage labour or selfemployment. This finding was in agreement with literature. A report from India and Nigeria for example, [32] indicated that education had a positive impact of income diversification improving the skills and understanding of farm households.

Age: The regression result shows a negative relationship between age of household head and income diversification, indicating that at a higher age, farmers tend to limit their source of income. Well above $48 \%$ of the interviewed farmers in this particular research were over 55 years old, an age of retirement. It is, therefore, an expected result that younger household heads tend to diversify more than their counterpart old age groups. The United Nation's report 2015 shows that the life expectancy in Africa slowed down during the late 1980 s and all through the 1990s, mainly because of the epidemics. Recently, the estimated level of life expectancy at birth for the continent reaching 59.4 years for the period between 2010 and 2015 [33]. This further justifies that older families have a low possibility of 
diversifying income. This is also in agreement with the literature. A report from Myanmar, and Zambia, for example [34, 35] showed that age of household head had a negative impact on crop diversification. However, other reports show that age has a positive relationship with diversity. For example, [35] reported from India that diversification increases with age but after a threshold, it starts declining.

Ethnicity, household size and dependency ratio: Nine ethnic groups are registered in Eritrea differentiated yet strongly bound by language, culture, production, trade and locations. The diversity in ethnicity is also a factor in income diversity. Ethnicity is an important determinant of participation in the rural non-farm income and can play both an enabling and constraining role [36].

Household size has a positive relationship with Income diversification. The larger the size of the household the more likely the household to be involved in diverse income sources. This is not, however, always true in that when the dependency ratio of the household is high the households may not diversify. In this particular study, it was found that the dependency ratio to be negatively related to income diversification. This shows that large household size with a high dependency ratio is less likely to diversify than otherwise. Therefore, in low income households, the factor that family size affects income diversification positively has to be seen in conjunction with the dependency ratio.

Gross Income and Income per-capita Household: Mixed results are reported in the literature concerning the impact of gross income on diversification. On the one hand, higher gross income induces diversification serving as a strengthening of risk-bearing capacity to the individual household. On the other hand, some households, whose source of income is more specialized, concentrating on a few sources, tend to minimize diversification. It all depends on the type of the source as well as the access to resources and the subsequent decision of the household. A study in Vietnam revealed that the poorer tend to be more diversified in terms of several income sources than the richer when the case is risk minimization. In terms of non-farm income, the poor are much less diversified than the rich for the fact that the poor often face more constraints compared to the rich due to unequal access to asset endowments to diversify income [37].

In this particular report, a higher gross income and high income per capita households have a positive impact on diversification, implying that high income groups can easily diversify their income with fewer restrictions to invest their income in diversified activities and a great capacity to bear risks. The positive relationship of income per capita with diversity can be attributed to households whose income has increased as a result of employing the extra household labour in diverse rural or urban occupations. Nevertheless, the diversification of income is not restricted to high income groups. When minimum risk activities are available, the low income groups will also be motivated to diversify their income with the limited resource they own, usually their labour, as a matter of necessity. The ability to diversify is, therefore, an important element for the poor in their effort to secure food for the family. Mixed results are obtained concerning whether diversification increases or decreases income inequality. [29], for example found that diversification had a highly skewed effect leading to inequality of income and well-being.

Farm size: There is a negative relationship between farm size and income diversification. Households with one extra hectare of farmland will have 0.29 SID less than they should have which is enough to put them one step lower in their diversity status. A household with larger farm size is likely to specialize in crop farm production and less likely to diversify. Not only all farm family members are preoccupied on their land and hence no spare time to look for a nonfarm job, but also they are likely to produce fairly enough food from their land. On the other hand households with limited farm size can early complete the farm work and leave out to search for employment on either on-farm or offfarm jobs. Hence, individual households with less farm size are likely to have a diversified 
source of income. This can be an entry point for policymakers to encourage specialization and farm intensification by a mere concentration of land on a few efficient and productive farmers. As a result, the extra rural labour created can be involved in several diverse occupations within and outside of the farm. A mixed result is reported in the literature concerning the impact of farm size on income diversification. A report from Ethiopia, for example, found that households with more land have fewer income sources, being more specialized in crop production [34]. On the other hand, a study in the Czech Republic, Poland and Hungary indicate that farming households tend to earn more from off-farm and related employment than from agriculture mainly due small farm size [36].

Access to Credit: Access to formal or informal credit induces income diversification. A strong positive relationship was found between access to credit and income diversification. Households are likely to increase their SID by 0.09 points that can help them diversify income when they have access to credit than not. One of the main constraints of small peasant farmers in the production of staple crops is the unavailability of a timely credit system. The peak periods for credit demand by farmers are during planting and harvesting time to purchase variable farm inputs such as fertilizer, pesticides, hired labour and harvesting materials. Access to credit at this point of time will motivate farmers to manage their farmland in due time and get the opportunity to look for an extra job in nonfarm activities that can increase diversification.

\section{Conclusion and Recommendation}

Using the SID, it was attempted to calculate the income levels and diversity status of regions and households in the study area. It was noted that diversification of income was pervasive in all regions and all levels of income groups considered. Comparison of income status among regions was carried out to understand whether relatively low income regions (LI) diversify more than their counterpart relatively high income regions (HI). Accordingly, regions of NRS, SRS, and Gash-Barka were roughly regarded as relatively low income regions whereas Anseba, Debub and Maekel were considered as relatively high income regions. Regardless of the income status that regions had, they were all on average categorized as having a relatively diversified income. This indicates that the contribution of other sources of income other than the agricultural source is significant. In other words, income sources of all regions are pretty highly diversified outside of crop and livestock production.

To determine the factors that affect income diversification, socioeconomic, demographic and institutional factors were assessed. Households, regardless of their income group, were identified as "not diversified", "slightly diversified, "moderately diversified" and "highly diversified" depending on their score of SID value. To this end, $68.75 \%$ of the households had from slightly to highly diversified income. The households were further identified by quartiles as "extremely low income", "low income", "moderate income" and "high income" groups. The average daily income per capita was found to be ERN 1.68, ERN 5,45, ERN 10.91, and ERN 39.73, respectively. It attempted to understand which income groups diversify more and why. Surprisingly, $34.7 \%$ of the "extremely low income" group and $73.8 \%$ of the "low income" group had slightly to highly diversified income. Of course the moderate and high income group were more diversified. $78.1 \%$ of the "moderate income" and $88.5 \%$ of the "high income" groups were slightly to highly diversified. This implies that although the better off, due to their ability to bear risk, diversify more than the poor or destitute, income diversification was pervasive in all levels of income groups as means of livelihood. Yet, the purpose of diversification for the poor was different from that of the well to do. The former diversifies for survival whereas the latter for wealth accumulation. 
Several demographic, socioeconomic and institutional factors were found to affect income diversification positively or negatively. The Tobit regression result indicates that many of the factors were determining income diversification. Level of education, ethnicity, household size, gross income, income per capita, and access to credit had a positive relationship with income diversity. On the other hand, the age of the household head, dependency ratio and size of land ownership had a negative relationship.

Larger family size households tend to have diversified income, but only when the dependency ratio is low. Households with larger farmland are less likely to have diversified income not only because of their preoccupation in the farmland but also due to the incentive of higher farm income from specialization. The higher income per capita and gross income motivates income diversification of households by creating the capacity to bear the risk. But still, high income groups with specialized occupation tend to have less diversified income. Still others with low income tend to diversify when there is an opportunity that minimizes risk.

Therefore, policy measures need to be directed towards creating a conducive condition taking into consideration the multiple sources of income of rural farming households. Policy recommendations should take into consideration the distinction between diversification as a necessity and diversification as a choice. The former requires a safety net (a short term solution) to mitigate the immediate needs of the majority poor and destitute groups of the society; whereas the latter requires a long term solution for sustainable rural development and agricultural transformation. These short-term solutions are as equally important as the long term ones as it is not possible to achieve a sustainable long term rural development without considering the day to day problems in the short run. To this end, government spending should give due consideration to nonfarm source of income in as much as to farming sources. Policies should promote vocational rural education and skill in as much as formal education is considered. Credit systems to finance rural non-farming and farming activities should be promoted.

\section{Reference}

1. T. Joshi, P.K., Gulati, A. Pratap, S. Birthal, Determinants and Policy Implications 39(24), 2457-2467 (2019)

2. Y. Gautam, P. Andersen, J. Rural Stud. 44, 239-249 (2016)

3. S. Alobo Loison, J. Dev. Stud. 51(9), 1125-1138 (2015)

4. G. Podesta, I. Fazey, N. Geeson, R. Hessel, K. Hubacek, D. Letson, D. Nainggolan, Elsevier 94(2013), 66-77 (2013)

5. D.F. Bryceson, Tracing Sectoral Transformation and Rural Income Diversification July, 1-11 (2018)

6. B. Davis, S. Di Giuseppe, A. Zezza, Policy Res. Work. Pap. 7108, 1-38 (2014)

7. D. Stifel, African J. Agric. Resour. Econ. 4(1), 82-109 (2010)

8. J.R. Davis, The Rural Non-Farm Economy, Livelihoods and their Diversification: Issues and options. Working Paper (Natural Resources Institute, Chatham, UK, 2004)

9. A. Angelsen et al., World Dev. 64(S1), S12-S28 (2014)

10. Country of Origin Information Report: Eritrea Country Focus (EASO, 2015)

11. Interim country strategy paper (i-csp) 2014-2016 (African Development Bank Group Eritrea, 2016)

12. Eritrea 2015, African Economic Outlook UNDP (UNDP, 2015)

13. M. Noordzij, G. Tripepi, F.W. Dekker, C. Zoccali, M.W. Tanck, K.J. Jager, Nephrol. 
Dial. Transplant. 25(5), 1388-1393 (2010)

14. P.S.B.P.K. Joshi, A. Gulati, L. Tewari, Agriculture Diversification in South Asia: Patterns, Determinants, and Policy Implications (2014)

15. O.A. Olounlade et al., Sustainability 12(3), 901 (2020)

16. N. Sharma, S.P. Singh, J. Econ. Soc. Dev. 9(1), 38-51 (2013)

17. N. Sharma, S.P. Singh, Agricultural diversification and contract farming in Punjab 1 (2004)

18. B.R.E.H. Hansen, Econometrics (University of Wisconsin, This Revision, 2019)

19. J.M. Wooldridge, MIT Press, 1-559 (2011)

20. R. Davidson, J. MacKinnon, Igarss 1, 1-5 (2014)

21. C. Hsiao, Analysis of panel data, second edition (2014)

22. S. Haggblade, P. Hazell, T. Reardon, World Dev. 38(10), 1429-1441 (1998)

23. The State of Food and Agriculture 2018. Migration, agriculture and rural developement (FAO, 2018)

24. K. Vatta, G. Singh, N. Sharma, P.B. Bhoi, Regional dimensions and determinants of income diversification in rural India 31, 33-46 (2018)

25. A.A. Reddy, C.R. Rani, T. Cadman, T.P. Reddy, M. Battarai, A.N. Reddy, A Study of Dokur since 1970s (2016)

26. World Economic Situation and Prospects (United Nations, FAO, Rome, 2019)

27. B. Archibald, S. Agyeman, S. Asuming-brempong, E.E. Onumah, Determinants of Income Diversification of Farm Households in the Western Region of Ghana 53(1), 55-72 (2014)

28. G.W. Kassie, S. Kim, F.P. Fellizarjr, Cogent Soc. Sci. 26, 1-16 (2017)

29. B.T. Reardon, Rural non-farm income income in developing countries (2010)

30. Mortality Report: Department of Economic and Social Affairs (United Nations, 2015)

31. A. Cho, A. T. Oo, S. Speelman, Assessment of Household Food Security through Crop Diversification in Natmauk Township (Myanmar) 